\section{ERRORS IN MEDICATION PRESCRIPTIONS IN PAEDIATRIC INTENSIVE CARE PATIENTS}

doi:10.1136/archdischild-2012-302724.0214

'B Maat, ${ }^{2} \mathrm{CW}$ Bollen, ${ }^{2} \mathrm{AJ}$ van Vught, ${ }^{1,3} \mathrm{ACG}$ Egberts, ${ }^{1} \mathrm{CMA}$ Rademaker. ${ }^{1}$ Department of Clinical Pharmacy, University Medical Center Utrecht; ${ }^{2}$ Department of Pediatric Intensive Care, Wilhelmina Children's Hospital, University Medical Center Utrecht; ${ }^{3}$ Department of Pharmacoepidemiology and Clinical Pharmacology, Utrecht Institute for Pharmaceutical Sciences, Utrecht University, Utrecht, The Netherlands

Background and aims Prescribing errors frequently occur in paediatric medicine, especially in paediatric intensive care units (PICUs). Computerized physician order entry (CPOE) systems may help to prevent these errors. This study examined the frequency, nature and determinants of prescribing errors in electronic and handwritten prescriptions in a PICU population.

Methods All prescriptions (electronic and handwritten) for children aged $0-18$ years hospitalized in a 14-bed PICU of a university medical center, The Netherlands, from February 2008 - December 2010, were prospectively collected and checked for prescribing errors and determinants (prescription-, patient- and medicationrelated) thereof.

Results 23,207 prescriptions for 659 patients were collected, of which 14,887 (64\%) were handwritten and 8,312 (36\%) electronically ordered. $6 \%$ of the prescriptions contained a therapeutic error and $54 \%$ was administratively incomplete (1-7 missing items per prescription). Electronically ordered prescriptions contained significantly less therapeutic and administrative errors than handwritten prescriptions $(p<0.001)$, mainly due to better legibility and completeness. More than $10 \%$ of the prescribed doses was outside the therapeutic range of the Dutch paediatric drug formulary. Important determinants of prescribing errors were handwritten prescriptions $(\mathrm{OR}=3.1 \quad[2.9-3.3])$, intravenous medication $(\mathrm{OR}=2.9$ [2.6-3.3]), the youngest of age (up to 1 month $\mathrm{OR}=1.2$ [1.1-1.4] and drugs affecting the musculo-skeletal system $(\mathrm{OR}=3.4$ [2.9-3.9]).

Conclusions PICU prescribing errors occur frequently. CPOE systems reduce error rates but do not fully prevent these. Data to support what is exactly needed to build better prescribing systems for PICU patients are scarce. This study provides information for improvements in electronic prescribing for PICU patients.

\section{THE ACCURACY IN INTERPRETING THE PAEDIATRIC ELECTROCARDIOGRAM AND THE NEED FOR FURTHER TRAINING}

doi:10.1136/archdischild-2012-302724.0215

1JS Jheeta, ${ }^{20}$ Narayan, ${ }^{3}$ T Krasemann. 'Department of Paediatrics and Child Health, Kings College Hospital; ' ${ }^{2}$ Department of Paediatrics and Child Health, Lewisham Hospital NHS Trust; ' ${ }^{3}$ Department of Paediatric Cardiology, Guy's \& St Thomas' NHS Foundation Trust, London, UK

Background and aims Accurate interpretation of the paediatric ECG is of great clinical significance and safety in managing unwell children. Paediatric trainees are assumed adequate knowledge in interpreting ECGs but there are limited studies demonstrating this.

Methods In an online survey-based questionnaire, participants interpreted 10 common clinical conditions with recognisable ECGs, including a normal paediatric and neonatal ECG. A brief educational page followed, then 10 different post-test ECGs on the same conditions. Brief demographics were collected on participant's grade and previous ECG training.

Results 764(n) participants accessed the online survey. Trainees completing only the first 10 ECGs we described as the '10-test', and those completing the full survey with 10 -test and 10-post-test ECGs after reading our educational material, as the '20-test'.
Abstract 215 Table 1

\begin{tabular}{|c|c|c|c|c|c|c|}
\hline Sub-Group & $\begin{array}{l}\text { Total } \\
\text { Participants }\end{array}$ & $\begin{array}{l}\text { 10-test } \\
\text { (score) }\end{array}$ & 10-test (n) & $\begin{array}{c}\text { 20-test } \\
\text { Pre-test } \\
\text { (score) }\end{array}$ & $\begin{array}{c}\text { 20-test } \\
\text { Post-test } \\
\text { (score) }\end{array}$ & 20-test (n) \\
\hline ST 1-3 & $n=195,25.6 \%$ & $60.5 \%$ & 137 & $63.7 \%$ & $77.0 \%$ & 92 \\
\hline ST 4-6 & $n=137,17.9 \%$ & $65.1 \%$ & 92 & $69.2 \%$ & $71.2 \%$ & 65 \\
\hline ST 7-8 \& Consultants & $n=185,24.2 \%$ & $68.0 \%$ & 130 & $69.8 \%$ & $74.4 \%$ & 92 \\
\hline $\begin{array}{l}\text { Others - includes ED/ } \\
\text { Anaesthetics/ANPS/GP }\end{array}$ & $\mathrm{n}=247,32.3 \%$ & $61.5 \%$ & 155 & $58.1 \%$ & $69.3 \%$ & 103 \\
\hline TOTAL & $\mathrm{n}=764$ & $61.0 \%$ & 514 & $65.6 \%$ & $73.0 \%$ & 352 \\
\hline
\end{tabular}

Conclusions Our study is the largest of its kind assessing ECG interpretation in UK Paediatric practice. Only 27.9\% participants had previous formal training, with training and our educational material reflecting improvements by upto $13 \%$. Without routine access to ECG interpretation by tertiary cardiology centres, more formal training needs incorporating into the UK Paediatric training program to accurately identify significant ECG anomalies, inform clinical decisions and optimise patient safety.

\section{MEDICATION ERRORS IN PAEDIATRICS: PATIENT, PILL AND PROCESS}

doi:10.1136/archdischild-2012-302724.0216

1J Maaskant, ${ }^{2} \mathrm{E}$ Zwart, 'D Bosman, ${ }^{3} \mathrm{R}$ Flint, ${ }^{2} \mathrm{H}$ Vermeulen. 'Women's and Children's Clinic; 'Quality Assurance and Process Innovation; ${ }^{3}$ Pharmacy, Academic Medical Center, Amsterdam, The Netherlands

Background and aims Medication errors, defined as preventable events that may lead to incorrect medication use or patient harm, is a big problem in healthcare. Especially children are considered to be at high risk of experiencing harm due to medication errors. Interventions to prevent errors have led to limited improvements. If, however, we could identify error prone situations, more effective interventions could be developed and thereby prevent patient harm. The purpose of this study was to establish the prevalence of harm due to medication errors categorized in characteristics of Patients and Pills in all phases of the medication Process.

Methods We investigated medication errors using a multifaceted approach including direct observations, and review of patients' files, pharmacy logs and voluntary incidents reports. All medication errors were classified in terms of (potential) patient harm.

Results We collected data of 426 patients admitted to five paediatric, non-ICU wards during three months. In 236 patients at least one medication error was identified: $55 \%(236 / 426)$. A total of 39 errors were harmful affecting 37 patients: 9\% (37/426).

Significantly more harmful medication errors were found in patients after surgery: $68 \%(25 / 37)$.

In $59 \%(23 / 39)$ of the $\mathrm{ADEs}$ analgesics were involved: non-opioids 49\% (19/39) and opioids 10\% (4/39). Prescribing and administrating were the most error prone activities: $28 \%$ (11/39) and $62 \%$ (24/39).

Conclusions Our results identified error prone Patients, $P$ ills and medication Process. This will guide future targeted interventions to improve medication safety for children.

\section{ACCEPTANCE AND PREFERENCE OF FOUR ORAL DOSAGE FORMS IN INFANTS AND PRE-SCHOOL CHILDREN IN THE NETHERLANDS}

doi:10.1136/archdischild-2012-302724.0217

1,2DA van Riet-Nales, ${ }^{2}$ AFAM Schobben, 2,3 TCG Egberts, ${ }^{3} \mathrm{C}$ Rademaker. ${ }^{1}$ Chemical Pharmaceutical Assessment, Medicines Evaluation Board; 'Department of Pharmacoepidemiology and Clinical Pharmacology, Utrecht Institute for Pharmaceutical Sciences; ${ }^{3}$ Department of Clinical Pharmacy, University Medical Center Utrecht, Utrecht, The Netherlands 